Relations industrielles

Industrial Relations

\title{
Motion and Time Study, by Ralph M. Barnes, New York, John Wiley and Sons, 1958, 4th Edition, 665 pp. \$9.25.
}

\section{Jean-Paul Deschênes}

Volume 14, numéro 1, janvier 1959

URI : https://id.erudit.org/iderudit/1022354ar

DOI : https://doi.org/10.7202/1022354ar

Aller au sommaire du numéro

Éditeur(s)

Département des relations industrielles de l’Université Laval

ISSN

0034-379X (imprimé)

1703-8138 (numérique)

Découvrir la revue

Citer ce compte rendu

Deschênes, J.-P. (1959). Compte rendu de [Motion and Time Study, by Ralph M. Barnes, New York, John Wiley and Sons, 1958, 4th Edition, 665 pp. \$9.25.] Relations industrielles / Industrial Relations, 14(1), 164-164.

https://doi.org/10.7202/1022354ar

Tous droits réservés @ C Département des relations industrielles de l’Université Laval, 1959
Ce document est protégé par la loi sur le droit d'auteur. L’utilisation des services d'Érudit (y compris la reproduction) est assujettie à sa politique d'utilisation que vous pouvez consulter en ligne.

https://apropos.erudit.org/fr/usagers/politique-dutilisation/ 
ties. Plus de $40 \%$ des conventions contiennent désormais des clauses dans lesquelles l'employeur renonce explicitement à exercer son droit de poursuite. L'auteur soutient que les intérêts mutuels des employeurs et des ouvriers ne peuvent pas être efficacement contournés par des mesures légales. La négociation collective libre est un système qui porte en lui-même beaucoup plus de force et de possibilités qu'on aurait pu l'imaginer ou le soupçonner il y a dix ans. La décadence de la loi TaftHartley est une illustration frappante de l'impossibilité de soumettre efficacement l'action privée collective au contrôle de l'intervention gouvernementale.

\section{Gaston Cholette}

Motion and Time Study, by Ralph M. Barnes, New York, John Wiley and Sons, 1958, 4th Edition, 665 pp. $\$ 9.25$.

Il existe certains volumes de base dans le domaine de la production, de la productivité et des salaires basés sur la production qu'on ne peut ignorer, et Motion and Time Study de Ralph M. Barnes en est un. Ce volume s'adresse surtout aux étudiants en génie industriel, mais il est aussi un outil précieux entre les mains des gérants d'entreprise et des chefs syndicaux. Les premiers apprendront à découvrir les amélionations possibles dans leur entreprise et les techniques à appliquer afin de les réaliser; les seconds comprendront mieux les intentions des patrons qui utilisent ces techniques et pourront apporter leur collaboration au besoin.

L'auteur reprend, dans cette nouvelle édition, les principes de base de l'étude des mouvements et des temps déjà discutés dans les éditions précédentes, mais leur champ d'application s'étend maintenant au travail indinect, à l'évaluation et au contrôle des machines et des procédés de fabrication. De plus, l'auteur ajoute cinq nouveaux chapitres qui portent sur les récents développements dans le champ du génie industriel et qui sont: motion study; mechanization and automation; mechanized time study and electronic data processing; systems of motion time data; work sampling; evaluation and controlling factors other than labor; et multi-factor wage incentive plans.
Donc les modifications apportées aux éditions précédentes et l'addition de cinq chapitres sur des développements récents justifient la lecture de cette nouvelle édition.

$$
\text { J.-P. D. }
$$

SARTAIN, A.Q., NORTH, A.J., STRANGE, J.R., \& CHAPMAN, H.M. Understanding Human Behavior. N.Y., McGraw-Hill, 1958.

Voici un livre pour le lecteur noninitié et pour l'étudiant qui couvre à peu près tous les phénomènes d'intérêt psychologique. Contrairement à d'autres volumes d'introduction à la psychologie, celui-ci ne s'est pas limité soit au côté expérimental soit au côté clinique soit au côté physiologique. La présentation est telle qu'elle aborde l'étude de l'homme « in totum »: personnalité, milieu social, famille, hérédité, physiologie, anthropologie culturelle, tout y passe.

Dans un cours d'introduction, on est souvent tenté de glisser sur l'aspect dynamique de la personnalité humaine. Fort heureusement, les auteurs ont réussi à en faire un exposé clair et acceptable. Ils n'ont pas hésité à aborder les points suivants: motivation, émotion, le moi, le comportement et les mécanismes de défense. Leur exposé est si bien conçu, qu'ils ont réussi à éviter les problèmes controversées tout en rapportant des faits sur lesquels les diverses théories psychologiques s'entendent.

Dans un ouvrage tel que celui-ci, les définitions sont nécessainement nombreuses. En génénal, celles du présent volume sont courtes, claires, et illustrées par des exemples bien choisis. Seul le chapitre no 15 semble faible à notre point de vure. Il $y$ est question $\mathrm{du}$ rôle de chaque individu et de son comportement social.

La présentation du volume et la mise en page sont impeccables. Quand le contenu devenait difficile à comprendre, l'éditeur a su aérer le texte par des illustrations. En général, la lecture en est facile.

C'est un livre que toute personne intéressée à l'étude de l'homme devrait avoir dans sa bibliothèquie.

C.-R. GIroux 